\title{
Changing Perceptions About Changes in the Teen Brain: An Overview
}

\author{
Carol Goldfus and Anit Karny-Tagger
}

\begin{abstract}
Education changes the brain. The purpose of this meta-review is to afford teachers access to the most upto-date research regarding principal neuro-processes of adolescent development and behavior to improve students' well-being and motivation in the classroom. This includes facets such as emotional, social, risk and reward mechanisms, stressors, technology, and learning. Understanding the scientific basis behind processes, such as learning and memory, empowers teachers with the knowledge to quantify the effects of their teaching on the brain, to facilitate successful learning, and to contribute to the present as well as future health and well-being of their adolescent students.
\end{abstract}

\section{Background}

Adolescence is a period characterized by change: hormonal, physical, psychological, and social (Choudhury, Charman, \& Blakemore, 2008). In recent years, with the increasing development and use of brain imaging technologies such as fMRI (functional magnetic resonance imaging), there has been an accumulation of findings on the structural and functional changes that occur in the developing adolescent brain. These findings have enabled scientists to study how the brain changes over time, and are beginning to shed light on some of the behavioral characteristics of teens. They suggest that the brain of a teenager really is different, that it is still very much a work in progress and functions quite differently from the brain of an adult. While there are areas of the brain that are fully developed, there are other areas responsible for executive functioning, like planning ahead and weighing priorities, that continue to develop well into our 20s (Johnson, Blum, \& Giedd, 2009).

These developments are extremely relevant for educators. By introducing cognitive neuroscience into education, teachers would be provided with a conceptual framework integrating neural, cognitive, linguistic, and developmental science, rather than only pedagogy. The changing adolescent brain is extremely malleable and sensitive to the effects of the environment. Although this makes adolescence a time of vulnerability, it also makes it an opportunity for education.

It has become apparent that connectedness to school during adolescence plays a significant role in building protective elements for positive educational outcomes and lower health-risk behaviors. Schools are accessible and relatively stable sites, and as such, can promote adolescent connectedness at a time characterized by transition and change in multiple areas, such as identity and peer and family relationships. Therefore, schools have an important role in affecting academic and vocational pathways, 
as well as present and future health and well-being (Bond et al., 2007).

There is enormous opportunity for brain science to shed light on the strengths of the adolescent brain (Johnson et al., 2009). Thus, the role of the teacher in the classroom is particularly significant during this period, since they have daily direct contact with students. Teachers can help adolescents acquire skills associated with areas of the brain that undergo the greatest change, such as self-control, goal setting, and planning. Teaching students emotional regulation strategies can help them cope with challenges so as to reduce their vulnerability to the adverse effects of the environment.

However, to achieve this, neuroscience has to be made accessible to educators. The aim of this article is to present an overview of state-of-the-art research about the teenage brain and to place this knowledge within an educational framework. Neuroscience does not provide teaching methods or procedures; it demands an integration of educational and pedagogical research. Understanding the functional brain is a first step to empirically developing teaching methods based on neuroscience in order to meet the needs of students in middle and secondary schools. This can lead to policies that promote adolescent health and well-being (Johnson et al., 2009).

The brain develops through its experiential interactions with the environment. We are born with the basic building blocks and blueprint intact, which are our genetic program and neurons that communicate with each other throughout life (Hardy, 2012). Learning involves the construction of a network of connections that is constantly sculpted through the strengthening of some synapses and the elimination of others (neuroplasticity). The timing and intensity of this evolution varies between brain regions and among people. Although this process continues throughout life, there are certain points in time that are more significant for learning certain skills; for example, language (Blakemore \& Frith, 2005). These are windows of opportunity for building new pathways as well as strengthening existing ones. They can be utilized by making a deliberate selection of our experiences and our activities (Goldfus, 2013).

The last two decades have revealed that one of these windows of opportunity is adolescence. Until recently, it was assumed that brain development was essentially complete by the age of twelve. We know today that the brain continues developing for much longer (Feinstein, 2011). Consequently, our view on this stage of life is changing. We are beginning to understand that childhood to adulthood is not a simple transition, but a vital developmental stage (Goddings, Heyes, Bird, Viner, \& Blakemore, 2012).

Although it was recognized that, during this period, children develop to a great extent, both socially and cognitively, not much thought was given to the effect of the brain's maturation on these developments (Choudhury et al., 2008). For many years, scientists could not detect a link between an improvement in cognitive performance and physical changes in the brain (Steinberg, 2011). In 1890, William James had already suggested a link between biology and behavior, but until recently, we could only speculate, since we did not have the tools to observe what was actually happening inside the brain. Research on the adolescent brain remained unreachable: "Wrapped in a tough leathery membrane, surrounded by a protective moat of fluid and completely encased in bone, the brain is well protected from falls, attacks from predators, and the curiosity of neuroscientists" (Giedd, 2008, p. 335). It was thought that adolescent 
behavior was due to hormonal activity and puberty (Goddings et al., 2012). However, although the timing of puberty and adolescence overlap, the terms are not the same. Rosenblum (1990) wrote that, "although one may define puberty in specific neuro-endocrinological terms,... adolescence is, of its essence, a period of transition rather than a moment of attainment, and so, it is difficult to distinguish its beginning or end" (Spear, 2000, p. 417).

The 20th century brought an array of technologies. The invention of functional magnetic resonance imaging (fMRI) launched a new era of adolescent neuroscience. It combines radio waves, strong magnetic fields, and sophisticated computer technology to produce accurate information about the physiology of the growing human brain. This procedure permits the safe scanning of healthy children, even more than once during their development (Giedd et al., 2010). This allows for a better understanding of the change in communication patterns connecting different regions of the brain during development (Steinberg, 2011).

In 1991, Dr. Jay Giedd began the first long-term, longitudinal study of the changes going on in the adolescent brain by using MRI scans of some 1,800 teenagers over a number of years (Giedd, 2003). The accumulated and analyzed data from these longitudinal studies yielded new information for researchers. It seems that although by the age of six our brain is about $95 \%$ of its adult size, maximum brain size does not mean brain maturity. There are still profound structural changes that take place within the brain during adolescence which continue until our mid-20s (Johnson et al., 2009).

Three main changes were revealed by the cumulative neuroimaging research of adolescents: overproduction of gray matter, synaptic pruning, and myelination.

\section{Over-Production of Gray Matter and Synaptic Pruning}

The first change is an overproduction of gray matter, which are the nerve cells themselves, and the formation of new connections, especially in the prefrontal cortex. This process of the thickening of the gray matter or synaptic density is called "synaptogenesis" and can last up to several months or years. It peaks at about the same time as puberty, age 11 in girls and age 12 in boys. This peak is followed by a decline, a process of competitive elimination called "pruning," where the excess connections are eliminated and a stabilization of synaptic density to adult levels is reached (Choudhury et al., 2008). This pattern extends to several related elements, such as the number of synapses, glucose use, and density of neurotransmitter receptors (Giedd, 2008). This inverted u-shaped process of thickening and thinning of gray matter (Blakemore \& Mills, 2014) is not a change in the actual number of brain cells, but the growth

in size and complexity of previously existing brain cells into extra branches, twigs, and roots, growing thicker and making more connections to other neural cells (Giedd, 2003). Giedd (2008) describes this maturation of the brain not as the addition of new letters, but of "combining earlier formed letters into words, and then words into sentences, and then sentences into paragraphs" (p. 340).

Scientists recognized that this process occurred in the womb and in the sensory motor associated areas of the brain during the first four years of life (Choudhury et al., 2008), but only after Giedd's (2003) 
longitudinal study has this second wave of synaptogenesis at the onset of puberty been noted. This process involves an increase in connectivity between the different brain components, which become more integrated. Giedd et al. (2008) noted that this growth in associative cognitive activity is, in fact, a representation of the attainment of knowledge (Feinstein, 2011).

The teenage brain goes through extensive pruning, a process which is greatly influenced by the environment, operating according to the principle of "use it or lose it," discarding unused synaptic connections and strengthening ones that are active. This process refines and sharpens the capabilities of the evolving nervous system, making it less encumbered and more efficient (Feinstein, 2011). This means there are fewer, more specialized nerve cells (Hinton, Miyamoto, \& Della-Chiesa, 2008). The important attribute to emerge from imaging studies is the extreme plasticity of the developing brain, allowing experiences to shape the brain (Giedd, 2003), which is relevant to all teachers involved in teaching adolescents.

\section{Myelination}

These experience-dependent changes of neuronal connections that are thought to be the biological basis of memory eventually accumulate to a significant reorganization in certain brain structures (Hinton et al., 2008). Scientist Gerald Edelman (1993) calls this "neural Darwinism," the survival of the fittest synapses.

The neuron pathways that survive "pruning" not only survive, but also get stronger and more stable; small pathways grow into better organized systems of "superhighways" (Steinberg, 2011, p. 70); they go on to be insulated and to improve their performance. A layer of myelin is formed around the axon, from supporting "glial" cells (Choudhury et al., 2008). Myelin is a fatty substance that acts like an insulator, speeding up the transmission of information by electrical impulses from neuron to neuron to a hundred times faster (Giedd, 2003). It appears white in MRI scans and so is sometimes called "white matter." Sensory and motor brain regions are fully myelinated in the first few years of life, but as Yakovlev and Lecours (1967) stated, frontal cortex neurons continue to be myelinated well into adolescence (Feinstein, 2011). Another white matter area that undergoes substantial changes during adolescence is the left arcuate fasciculus, which connects Wernicke's area (reception of speech) with Broca's area (production of speech). A study revealed that the white matter providing connections between the hippocampus (related to long-term memory [LTM]) and the frontal cortex was especially active during adolescence; this could suggest an increasing ability to draw upon memories of past events in decision making (Giedd, 2004). Clear connections have been established between sensory and motor functions and the myelination of their neuroanatomical foundations (Giedd, 2003).

Acknowledgment of the importance of white matter growth for brain function has encouraged the development of new imaging techniques; for example, diffusion tensor imaging (DTI) and magnetization transfer (MT), which can be used to evaluate myelination and lucidity of white matter tracts. These new methods further confirm an increase in white matter arrangement throughout adolescence, which correlates in specific brain regions with cognitive improvements in language (Nagy, Westerberg, \& 
Klingberg, 2004), in reading (Deutsch et al., 2005), in the ability to inhibit a response (Liston et al., 2006; Nagy, Westerberg, \& Klingberg, 2004), and in memory (Giedd et al., 2010).

As myelination expands throughout the adolescent brain, an increase in working memory and ease and competence is experienced with learning (Feinstein, 2011). In practical terms, the activities in which an adolescent participates are the ones that are myelinated. Whether it is playing sports, a computer game, a musical instrument, or reading, or riskier activities such as smoking or using drugs, the neural pathways that are associated with those activities are the ones that will be hardwired in the adolescent's brain. Thus, the activities of the adolescent can have a powerful influence on the ultimate physical structure of the brain (Giedd, 2003).

Another important modification that is characteristic of adolescence is a shifting balance between competing neural systems. Although synaptic pruning occurs throughout infancy, childhood, and adolescence, different brain regions are pruned at different points of development (Steinberg, 2011). This means that various cognitive and emotional networks mature at a different pace (Choudhury et al., 2008). The direction of brain maturation is from bottom up and inside out. Gradually the proportion of activity, in a range of cognitive tasks, shifts from the limbic/subcortical to the frontal lobes (Giedd, 2008). The most profound changes in the adolescent brain take place in the front part of the brain (Steinberg, 2011). The prefrontal cortex, with its executive functioning, is assumed to be associated with abilities such as response inhibition, attention, regulation of emotion, organization, and long-range planning. These faculties are thought to rely a great deal on the frontal lobe network. Basic abilities, such as those involving memory, attention, and logical reasoning, can develop by the age of 15; others, like thinking ahead, balancing risks and rewards, mature relatively late, even into the mid-20s (Giedd, 2008). The two main changes that take place are:

- A more focused activation within the prefrontal cortex.

- The activation of several brain regions simultaneously and in coordination within it as well as with other regions like the limbic system (Steinberg, 2011).

Additionally, some changes in limbic (emotional) reward and motivational systems appear to be linked with the beginning of puberty, while other changes transpire earlier or well after the arrival of puberty (Goddings et al., 2012).

\section{Mentalization}

Choudhury (2010) proposed that adolescence is a time of particular cultural susceptibility, and Crone and Dahl (2012) noted that the impact of puberty on the brain makes adolescents particularly sensitive to their social environments (Blakemore \& Mills, 2014). Frith (2008) explains that social cognition involves the ability to make sense of the world through processing signals generated by members of the same species (Blakemore \& Mills, 2014). Some call this ability "mentalization," which emerges from developmental changes in the physical structure of the brain. Increase in white matter speeding communication between neurons, growing complexity of brain networks suggested by gray matter 
changes, and environmentally sensitive plasticity are all essential aspects in a child's ability to mentalize and maintain the adaptive flexibility necessary for healthy progress into adulthood (Giedd, 2003).

One of the first studies to investigate the influence of puberty on the "mentalizing network" of the social brain was a study by Goddings and her colleagues (2012) that explored the influence of puberty on social emotion processing in adolescence. The sample consisted of 42 female adolescents (11 to 13 years) at different measured stages of puberty; their brains were scanned during a mentalizing task. It was observed that while some changes that happen in the "mentalizing" network were affected by the hormone activity of puberty, other changes were related to chronological age development and were not affected by puberty. Furthermore, researchers speculated that the limbic regions contain large numbers of sex hormone receptors that are affected by the increase in sex hormones during puberty, which might have a direct effect on the activation of the anterior temporal cortex (ATC) in social cognition tasks. Researchers suggested that the changes or decreases in activity in the dorsomedial prefrontal cortex (DMPFC) region, which are not affected by the hormonal changes of puberty, might be the result of age-dependent neuroanatomical maturation; in other words, experience. The more experience an adolescent gains the less neuro-cognitive effort he or she needs to perform prefrontal-based cognitive operations. But the important point is that changes in social brain activity during adolescence are not under the control of a single system. Instead, these changes may be related to both age and puberty in different ways, and have both biological and environmental drivers (Goddings et al., 2012)

Some basic perceptual social cognitive processes develop rapidly from birth, such as face recognition (Farroni et al. 2005), biological motion detection (Pelphrey \& Carter, 2008), and joint attention (Carpenter, Nagello, \& Tomasello, 1998). Recent studies have shown that the more complex social processes, such as understanding the mental states of others (Blakemore et al., 2007), social emotional processing (Burnett, Bird, Moll, Frith, \& Blakemore, 2009) and negotiating complex interpersonal decisions (Crone, 2013), continue to develop throughout adolescence (reviewed in Apperly, 2010; Blakemore, 2012).

The emotional brain systems of adolescents are changing; their prefrontal cortex is developing and they process social signals differently than adults or children. "Brain maturation involves a progressive 'frontalization' of function whereby the prefrontal cortex gradually assumes primary responsibility for many of the cognitive processes initially performed by more primitive subcortical and limbic structures" (Yurgelun-Todd \& Killgore, 2006, p. 194).

Yurgelun-Todd and Killgore (2006) showed that adolescents also differ from adults in their ability to read and understand emotions in the faces of others. In fact, teens and adults actually use different regions of the brain to respond to certain tasks. In a study they conducted, a researcher displayed pictures of people with fearful expressions to teenagers between the ages of 11 and 17 while scanning their brains using fMRI. They found that, compared to adults, the frontal lobes of teens (the seat of goal-oriented rational thinking) are less active and their amygdala (a structure in the temporal lobe that is involved in discriminating fear and other emotions) is more active. One hundred percent of adults identified fear, while fewer than $50 \%$ of adolescents did. The teens often misread facial expressions, with those under 
14 years of age more often seeing sadness, anger, or confusion, instead of fear. Older teenagers were more often correct and showed a progressive shift of activity from the amygdala to the frontal lobes. The results suggest that in adolescents the insight, reasoning, and judgment power of the frontal cortex is not being used during the task as it is in adults. Teens process information differently from adults and they respond differently to the outside world (Yurgelun-Todd \& Killgore, 2006).

\section{The Social/Emotional Brain}

It is no secret that teenagers like to spend much of their time with other adolescents. As adolescents mature, relationships with friends become more central to their life. It is a basic human need and important for social integration and a sense of belonging to a group of peers. The peer group is an important source of social support for adolescents during this potentially confusing time, with whom they can share similar feelings and feel they are not alone, especially in light of the process of distancing from parents that characterizes this period (Newman, Lohman, \& Newman, 2007; Sroufe, Cooper, \& DeHart, 1996; Brown \& Larson, 2009). Peers can function as role models, allowing alternative models that encourage the formation of self-identity (Steinberg, 2011). Peer evaluation affects adolescents' feelings of social or personal worth (Blakemore \& Mills, 2014), but is also a source of temptation and risk, and can cause feelings of isolation and depression if the adolescent feels unaccepted by friends or is the victim of bullying (Vaillancourt et al., 2008). In their study, Hartup and Stevens (1997) showed a link between the existence of social support and an adolescent's positive self-esteem, sense of belonging, and feeling optimistic about future interpersonal relationships (cited in Valkenburg \& Peter, 2009). Brown and Larson (2009) indicate that adolescents learn to develop an intimate relationship with peers that includes openness, honesty, loyalty, and trust. There is also a gradual attraction to the opposite sex (or the subject of attraction), enabling the development of romantic relationships of love and trust (Steinberg, 2011).

Furthermore, teenagers generally become sexually active during adolescence, enabling expressions of sexual feelings, physical enjoyment of contact with others, which exposes them to questions of sexual morality and sexual identity (Steinberg, 2011). There are also expectations from parents and teachers, and society in general, that teens take more responsibility for their own lives, and contribute to others (Ziv, 1984). In order to become productive members of society, adolescents must learn to navigate these social complexities.

\section{Stress}

Adolescence is a time of significant developmental changes from childhood to adulthood, a transition which Dorn and Chrousos (1993) perceived as a chronic state of threatened stability (Spear, 2000); their ability to exercise effective cognitive and emotion regulation is still relatively immature (Somerville, Jones, \& Casey, 2010). It is imperative for adolescents to develop their adaptive response skills in order to become stable independent adults. Therefore, adolescence can be considered almost by definition as a stressful life stage (Spear, 2000). It is a period characterized by a heightened tendency to experience negative and widely fluctuating mood states (Somerville et al., 2010); both the type of stressors and the 
responses made are in flux (Romeo, 2013). What may seem like a mild incident to an adult is perceived as an intense emotional trigger in adolescents, leading to negative effects (Somerville, 2010). The heightened vulnerability to psychiatric conditions during adolescence has been proposed to relate to genetically preprogrammed neural development at the same time as new stresses and challenges emerge in the environment (Andersen \& Teicher, 2008; Leussis \& Andersen, 2008; Blakemore \& Mills, 2014). The majority of anxiety disorders emerge during adolescence (Den \& Richardson, 2013). Most seem to be in part precipitated by situations that are stressful life events in adolescence. These can be changing schools, rapid growth and change in body shape, family relationships (preadolescents), the social stress of negative peer-related experiences (early adolescence), academic issues (older adolescence) (Spear, 2000). Spear (2009) and others have associated pubertal maturation with elevated physiological reactivity to emotional cues, and Schulz, Molenda-Figueira, and Sisk (2009), with adaptations in limbic circuitry (Pattwell, Lee, \& Casey, 2013). Enhanced plasticity creates greater vulnerability (Andersen, 2003). A lack of prefrontal control may lead to reduced emotional regulation capacities, resulting in unreserved highly emotional responses (Somerville et al., 2010). All these challenges can be overwhelming for the adolescent (Spear, 2000).

Two hormonal systems are activated to help an individual cope when faced with stressors. The first is an immediate response of the "fright-flight" reaction, while the second is a slower process mediated by the hypothalamic-pituitary-adrenal (HPA) axis which secretes glucocorticoids (i.e., cortisol) (Romeo, 2013). These are responsible for the different adaptive physiological and behavioral responses to stress, such as mobilizing energy stores, enhancing immune reactions, and increasing learning and memory abilities (Romeo, 2013). Exposure to mild stress during pubertal transition in rats motivates them to accelerate behavior toward independence such as increased risk-taking and novelty seeking, and decreased anxious behavior in later adolescence. Human adolescents within socially unpredictable environments showed decreased short-term physical and mental health. They also adopt faster life history strategies, such as decreased health and less sexual restrictedness (Brumbach, Figueredo, \& Ellis, 2009; Blakemore \& Mills, 2014). However, chronic exposure to stress-induced hormones can lead to short- and long-term maladaptive outcomes, such as metabolic disorders, as well as impaired immune and cognitive functions. Giedd and Rapoport (2010) stated that recent neuroimaging studies indicate that the areas that are most sensitive to stress in adulthood (specifically the hippocampus, prefrontal cortex, and amygdala) all continue to mature during adolescence (Romeo, 2013).

Finally, emotion is extremely relevant to education, especially in the context of stress. Low levels of stress can be positive and may even contribute to motivation. However, elevated levels of frequent or extended stress can be toxic to the brain. Neuroscience research informs us that positive social interactions releases oxytocin. This hormone assists our ability to connect and bond with others and reduces stress (Feinstein, 2011; Steinberg, 2008).

\section{Risk and Reward}

Adolescence is frequently characterized as a health paradox. On the one hand, it is a time of increased physical and mental capabilities. On the other, however, generally, mortality and injury rates increase 
significantly from childhood to adolescence, often due to preventable causes (Willoughby, Good, Adachi, Hamza, \& Tavernier, 2013). These may result from decisions and actions that give rise to an increase in occurrences of unintentional injuries and violence, alcohol and drug abuse, unintended pregnancy and sexually transmitted diseases (Rodrigo, Padrón, De Vega, \& Ferstl, 2014). Researchers propose that the reason for this lies in the nucleus accumbens (Galvan et al., 2006), in the ventral striatum. These pleasure-seeking reward systems in the teen's brain develop faster than the frontal cortex (the "CEO"), which regulates delay of gratification, thinking ahead, and judgment. This gap in timing may help explain some of the typical behavior during this period of life. This functional transformation involves the limbic system with changes in levels of several neurotransmitters, dopamine that is associated with how we perceive reward, and serotonin which is associated with our moods (Steinberg, 2011).

The reward centers of the adolescent brain are a great deal more active than those of children or adults, making teens more prone to risky, impulsive behaviors (Hoboken et al., 2011; Somerville et al., 2010). They do evaluate risk; they just weigh risk and reward differently (Steinberg, 2011), leaning more toward reward. They prefer decisions that provide immediate reward, particularly social rewards, which teens might be more susceptible to (Darby, Del Piero, Immordino-Yang, Kaplan, \& Margolin, 2015).

They are much more likely to make risky decisions in the presence of peers, when there is potential for peer approval or a way to avoid social exclusion (Blakemore \& Robbins, 2012; Blakemore \& Mills, 2014). Susceptibility to peer influence rises during mid-adolescence (Steinberg, 2011). Gardner and Steinberg (2005) examined how the presence of peers is likely to influence adolescents to take risks in a driving game. Three age groups participated: adolescents (13 to 16 years), young adults (18 to 22 years), and adults (24+ years). When alone, they all took the same number of risks, but when in the presence of their peers, adolescents took significantly more risks than the adult or youth groups (Blakemore \& Mills, 2014).

Recent studies emphasize the association between different neural systems as well as on how social context and individual traits affect these behaviors (Willoughby et al., 2013). An important point to remember is that sometimes taking a risk may result in the preferred outcome (Blakemore \& Mills, 2014). The adolescent brain's extreme plasticity makes this period a window of opportunity for learning (Blakemore \& Mills, 2014). New findings about the brain can be an opportunity for new improved approaches to teaching (Posner \& Rothbart, 2005). Educators should provide meaningful learning experiences with ongoing guidance that enables students at all levels to advance toward mastery of a common set of skills (Hinton et al., 2012). Student-centered approaches to learning require pupils to be self-directed and responsible for their own learning, which demands executive functioning skills such as goal setting, planning, and monitoring progress (Hinton et al., 2012). The prefrontal lobe responsible for control and monitoring, organization, and prioritizing, is still developing. Thus, educators ought to teach the executive functions and not take for granted that the middle school students know these functions. This knowledge has implications for the classroom. This is an example of how awareness of prefrontal lobe development creates the understanding to teach executive skills to automaticity and how the teaching environment can provide the necessary cues for coping with the academic world. 
It is important to remember that areas in the brain which are not used will be eliminated (Choudhury et al., 2008). Furthermore, teachers should take into account the emotional brain; teens are sensitive to reward (dopamine) (Spear, 2000), making learning a positive rewarding experience. It is important to remember that environments that promote positive relationships and a sense of community promote learning (Hinton et al., 2012). This is especially true in adolescents who are motivated by social rewards (peers' acceptance) (Guyer, Choate, Pine, \& Nelson, 2012), and more vulnerable to stress (Blakemore \& Mills, 2014). The amygdala is accessed directly for decision-making, creating vulnerability to stress. Knowledge of these facts provides educators with an opportunity to help students thrive academically by creating a learning environment that shelters students from toxic stress (Hinton et al., 2012).

Educators might have limited influence on students' friendships, but they can use group work assignments in class. This strategy can create a stress-free learning environment by facilitating positive social interactions, which can encourage a sense of community to counteract loneliness and teach students emotional regulation strategies (Feinstein, 2011; Hinton et al., 2012).

Emotion can help students remember better (Immordino-Yang \& Fischer, 2009); therefore, it can be valuable to use it as part of lesson content. Teens have less ability to manage or read emotions in others, so teachers should make sure that their students understand what they mean, and what they expect. The teen brain is programmed to make connections between different parts of itself (Steinberg, 2008) Thus, it might be productive to present tasks that combine several abilities, promoting those connections. Teens are still learning how to understand (i.e., abstract thinking is newly developed); teachers can connect lesson content to their interests, to what they already know and enjoy. Give them time to process new information. Teens are novelty seekers, so it might be constructive to diversify lesson resources.

\section{Conclusion}

This paper makes a case for empowering teachers with updated information from neuroscience so that they might apply this knowledge in their teaching. This knowledge can allow teachers a better understanding of how to manage cognitive, social, and emotional difficulties that can be characteristic of this age. The emotional and social dimensions of learning may have a deeper impact on students' lives than what appears on the surface, especially at this age (Immordino-Yang, 2011). The environment or experiences created by teachers have an impact on the development of the physical structure of their students' brains. Providing teachers with this new knowledge about adolescent neurological development, combined with their own hands-on experience, can provide them with the opportunity to modify their educational practices which, in turn, can help develop new educational theories that capitalize on the unique neurological characteristics of adolescence. 


\section{References}

Andersen, S. L. (2003). Trajectories of brain development: point of vulnerability or window of opportunity? Neuroscience \& Biobehavioral Reviews, 27, 3-18.

Andersen, S.L., \& Teicher, M.H. (2008). Stress, sensitive periods and maturational events in adolescent depression. Trends in Neuroscience, 31,183-191.

Apperly, I. A. (2010). Mindreaders: The cognitive basis of "theory of mind". Hove, UK: Psychology Press.

Blakemore, S.-J. (2012). Imaging brain development: the adolescent brain. Neuroimage, 61(2), 397-406.

Blakemore, S.-J., Den Ouden, H., Choudhury, S., \& Frith, C. (2007). Adolescent development of the neural circuitry for thinking about intentions. Social Cognitive and Affective Neuroscience, 2, 130-139.

Blakemore, S.-J., \& Frith, U. (2005). The learning brain: Lessons for education: A precis. Developmental Science, 8, 459-465.

Blakemore, S.-J., \& Mills, K. L. (2014). Is adolescence a sensitive period for sociocultural processing? The Annual Review of Psychology, 65, 187-207.

Blakemore, S.-J., \& Robbins, T. W. (2012). Decision-making in the adolescent brain. Nature Neuroscience, 15, 1184-1191.

Bond, L., Butler, H., Thomas, L., Carlin, J., Glover, S., Bowes, G., et al. (2007). Social and school connectedness in early secondary school as predictors of late teenage substance use, mental health, and academic outcomes. Journal of Adolescent Health, 40(4), 357.e9-e18.

Brown, B. B., \& Larson, J. (2009). Peer relationships in adolescence. In Lerner, R. M. \& Steinberg, L. (Eds.), Handbook of adolescent psychology, Vol 2: Contextual influences on adolescent development (pp. 74-103). Wiley.

Brumbach, B.H., Figueredo, A.J., \& Ellis, B.J. (2009). Effects of harsh and unpredictable environments in adolescence on development of life history strategies: A longitudinal test of an evolutionary model. Human Nature, 20, 25-51.

Burnett, S., Bird, G., Moll, J., Frith, C., \& Blakemore, S.-J. (2009). Development during adolescence of the neural processing of social emotion. Journal of Cognitive Neuroscience, 21, 1736-1750.

Carpenter, M., Nagell, K., \& Tomasello, M. (1998). Social cognition, joint attention, and communicative competence from 9 to 15 months of age. Monographs of the Society for Research in Child Development, 63(i-vi), 1-143.

Choudhury, S. E. (2010). Culturing the adolescent brain: What can neuroscience learn from anthropology? Social Cognitive and Affective Neuroscience, 5, 159-167.

Choudhury, S. E., Charman, T., \& Blakemore, S.-J. (2008). Development of the teenage brain. Mind, Brain and Education, 2, 142-147.

Crone, E.A. (2013). Considerations of fairness in the adolescent brain. Child Development Perspectives, 7(2), 97-103. 
Crone, E. A., \& Dahl, R. E. (2012). Understanding adolescence as a period of social-affective engagement and goal flexibility. Nature Reviews. Neuroscience, 13(9), 636-650. Retrieved from http://doi.org/10.1038/nrn3313

Darby, S., Del Piero, L. Immordino-Yang, M. H., Kaplan, J., \& Margolin, G. (2015). Neural correlates of adolescents' viewing of parents' and peers' emotions: Associations with risk-taking behavior and risky peer affiliations. Social Neuroscience, 10(6), 592-604, doi:10.1080/17470919.2015.1022216

Den, M. L., \& Richardson, R. (2013). Enhanced sensitivity to learning fearful associations during adolescence. Neurobiology of Learning and Memory, 104, 92-102.

Deutsch, G. K., Dougherty, R. F., Bammer, R., Siok, W. T., Gabrieli, J. D., \& Wandell, B. (2005). Children's reading performance is correlated with white matter structure measured by diffusion tensor imaging. Cortex, 41, 354-363.

Dorn, L. D., \& Chrousos, G. P. (1993). The endocrinology of stress and stress system disorders in adolescence. Endocrinology and Metabolism Clinics of North America, 22, 685-700.

Edelman, G. M. (1993). Neural Darwinism: Selection and reentrant signaling in higher brain function. Neuron 10, 115-125.

Farroni, T., Johnson, MH, Menon, E., Zulian, L., Faraguna, D., \& Csibra, G. (2005). Newborns' preference for face-relevant stimuli: Effects of contrast polarity. Proceedings of the National Academy of Sciences, $102,17245-17250$.

Feinstein, S. (2011). The teenage brain and technology. LEARNing Landscapes 5, 71-84.

Galvan, A., Hare, T. A., Parra, C. E., Penn, J., Voss, H., Glover, G., et al. (2006). Earlier development of the accumbens relative to orbitofrontal cortex might underlie risk-taking behavior in adolescents. Journal of Neuroscience, 26, 6885-6892.

Gardner, M., \& Steinberg, L. (2005). Peer influence on risk taking, risk preference, and risky decision making in adolescence and adulthood: An experimental study. Developmental Psychology, 41(4), 625635.

Giedd, J. N. (2003). The anatomy of mentalization: A view from developmental neuroimaging. Bulletin of the Menninger Clinic, 67, 132-142.

Giedd, J. N. (2004). Structural magnetic resonance imaging of the adolescent brain. Annals New York Academy of Sciences, 1021,77-85.

Giedd, J. N. (2008). The teen brain: Insights from neuroimaging. Journal of Adolescent Health, 42, 335343.

Giedd, J.N., \& Rapoport, J.L. (2010). Structural MRI of pediatric brain development: What have we learned and where are we going? Neuron, 67, 728-734.

Giedd, J. N., Stockmam, M., Weddle, C., Liverpoo, M., Alexander-Bloch, A., \& Gregory, L. (2010). Anatomic magnetic resonance imaging of the developing child and adolescent brain and effects of genetic variation. Neuropsychology Review, 20, 349-361.

Goddings, A.-L., Heyes, S. B., Bird, G., Viner, R. M., \& Blakemore, S.-J. (2012). The relationship between puberty and social processing. Developmental Science, 15, 801-811. 
Goldfus, C. (2013). Cognitive intervention to enhance foreign language reading comprehension in adolescents with dyslexia difficulties. In D. Martin, Researching dyslexia in multilingual settings: Diverse perspectives (pp. 55-73). Bristol: Multilingual Matters.

Guyer, A.E., Choate, V.R., Pine, D.S., \& Nelson, E.E. (2012). Neural circuitry underlying affective response to peer feedback in adolescence. Social Cognitive and Affective Neuroscience, 7, 81-92.

Hardy, K. (2012). Growing and developing. In Kay, J. (Ed.). Good practice in the early years (pp. 116148). New York: Continuum International Publishing Group.

Hartup, W.W., \& Stevens, N. (1997). Friendship and adaptation across the life span. Curr Dir Psychol Sci., 8(3), 76-79. doi:10.1111/1467-8721.00018

Hinton, C., Fischer, K. W., \& Glennon, C. (2012). Mind, brain, and education: Jobs for the future. U.S.A.

Hinton, C., Miyamoto, K., \& Della-Chiesa, B. (2008). Brain research, learning and emotions: Implications for education research, policy and practice. European Journal of Education, 43, 87-103.

Hoboken, N.J., Chein, J., Albert, D., O’Brien, L., Uckert, K., \& Steinberg, L. (2011). Peers increase adolescent risk taking by enhancing activity in the brain's reward circuitry. Developmental Science, 14(2), F1-F10. Retrieved from http://doi.org/10.1111/j.1467-7687.2010.01035.x

Immordino-Yang, M. H. (2011). Implications of affective and social neuroscience for educational theory. Educational Philosophy \& Theory, 43(1), 98-103. doi:10.1111/j.1469-5812.2010.00713.x

Immordino-Yang, M. H., \& Fischer, K. W. (2009). Neuroscience bases of learning. In V. G. Aukrust (Ed.), International Encyclopedia of Education, 3rd Edition, Section on Learning and Cognition. Oxford, England: Elsevier.

Johnson, S. B., Blum, R. W., \& Giedd, J. N. (2009). Adolescent maturity and the brain: The promise and pitfalls of neuroscience research in adolescent health policy. Journal of Adolescent Health, 45, 216-221.

Leussis, M.P., \& Andersen, S.L. (2008). Is adolescence a sensitive period for depression? Behavioral and neuroanatomical findings from a social stress model. Synapse, 62, 22-30.

Liston, C., Watts, R., Tottenham, N., Davidson, M. C., Niogi, S., Ulug, A. M., et al. (2006). Frontostriatal microstructure modulates efficient recruitment of cognitive control. Cerebral Cortex, 16, 553-560.

Nagy, Z., Westerberg, H., \& Klingberg, T. (2004). Maturation of white matter is associated with the development of cognitive functions during childhood. Journal of Cognitive Neuroscience, 16, 12271233.

Newman, B.M., Lohman, B.J., \& Newman, P.R. (2007). Peer group membership and a sense of belonging: Their relationship to adolescent behavior problems. Adolescence, 42, 1-24.

Pattwell, S. S., Lee, F. S., \& Casey, B. J. (2013). Fear learning and memory across adolescent development. Hormones and Behavior, 64, 380-389.

Pelphrey, K.A, \& Carter, E.J. (2008). Charting the typical and atypical development of the social brain. Developmental Psychopathology, 20, 1081-1102.

Posner, M.I., \& Rothbart, M.K. (2005). Influencing brain networks: implications for education. Trends in Cognitive Sciences, 9(3), 99-103. 
Rodrigo, M. J., Padrón, I., De Vega, M., \& Ferstl, E. C. (2014). Adolescents' risky decision-making activates neural networks related to social cognition and cognitive control processes. Frontiers in Human Neuroscience, 8,60 .

Romeo, R. D. (2013). The teenage brain: The stress response and the adolescent brain. Current Directions in Psychological Science, 22, 140-145.

Schulz, K.M., Molenda-Figueira, H.A., \& Sisk, C.L. (2009). Back to the future: The organizationalactivational hypothesis adapted to puberty and adolescence. Hormones and Behavior, 55, 597-604.

Somerville, L. H., Jones, R. M., \& Casey, B. J. (2010). A time of change: Behavioral and neural correlates of adolescent sensitivity to appetitive and aversive environmental cues. Brain and Cognition, 72, 124133.

Spear, L. P. (2000). The adolescent brain and age-related behavioral manifestations. Neuroscience \& Biobehavioral Reviews, 24, 417-463.

Spear, L. P. (2009). Heightened stress responsivity and emotional reactivity during pubertal maturation: Implications for psychopathology. Development and Psychopathology, 21, 87-97.

Sroufe, A. L., Cooper, G. R., \& DeHart, B. G. (1996). Child development: Its nature and course (3rd ed.). McGraw Hill.

Steinberg, L. (2008). A social neuroscience perspective on adolescent risk-taking. Developmental Review, 28, 78-106.

Steinberg, L. (2011). Adolescence. New York: McGraw-Hill.

Vaillancourt, T., Duku, E., Decatanzaro, D., Macmillan, H., Muir, C., \& Schmidt, LA (2008). Variation in hypothalamic-pituitary-adrenal axis activity among bullied and non-bullied children. Aggressive Behaviour, 34, 294-305.

Valkenburg, P. M., \& Peter, J. (2009). Social consequences of the internet for adolescents: A decade of research. Current Directions in Psychological Science, 18, 1-5.

Willoughby, T., Good, M., Adachi, P. J., Hamza, C., \& Tavernier, R. (2013). Examining the link between adolescent brain development and risk taking from a social-developmental perspective. Brain and Cognition, 83, 315-323.

Yurgelun-Todd, D. A., \& Killgore, W. D. (2006). Fear-related activity in the prefrontal cortex increases with age during adolescence: A preliminary fMRI study. Neuroscience Letters, 406, 194-199.

Ziv, A. (1984). Adolescence. Tel-Aviv: Masada. (in Hebrew) 


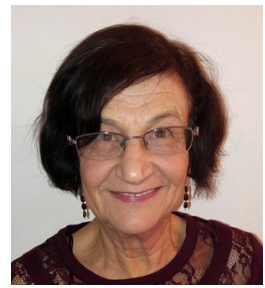

Carol Goldfus received her doctorate from the University of Birmingham, England and postdoctoral research in neuroscience from Haifa and Bar Ilan University, Israel. She is currently a research fellow at the University of the Free State, South Africa. Her research interests include cognitive intervention in adolescents with languagerelated disabilities, the development of metacognition, reading comprehension, and memory. Within the field of teacher education, she is developing and researching the new field of Educational Neuroscience.

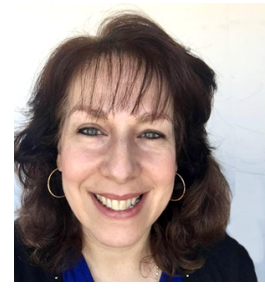

Anit Karny-Tagger completed a B.A. in English Literature and Political Science at Tel-Aviv University. She has taught in middle school education for several years and recently completed a Graduate Degree in education from the Levinsky College of Education, in Tel Aviv. She is currently an independent researcher focusing on middle school education and the teenage brain. 